\title{
Experimental and Numerical Investigation of a Double-Acting Offshore Vessel Performance in Level Ice
}

\author{
Biao $\mathrm{Su}^{1}$ Roger Skjetne ${ }^{1}$ Tor Einar Berg ${ }^{2}$
}

${ }^{1}$ Department of Marine Technology, Norwegian University of Science and Technology, Trondheim, Norway. E-mails: Biao.Su@sintef.no, Roger.Skjetne@ntnu.no

${ }^{2}$ MARINTEK, Trondheim, Norway. E-mail: Tor.Berg@marintek.sintef.no

\begin{abstract}
In this paper a numerical model and experimental data are used to investigate the level ice performance of a double-acting intervention vessel. The icebreaking capability and maneuverability in level ice are analyzed by evaluating the behavior of the vessel when it is running both ahead and astern. The paper also presents the implementation of a random crack size model for more realistic icebreaking behavior, giving more consistent evaluation of the vessel's performance in various ice conditions. The numerical simulations are firstly conducted in model-scale for a direct comparison with the experimental results. The scaling of ship speed and ice resistance is then discussed by comparing the simulation results in both full-scale and model-scale. The effect on the vessel's performance of the different properties of scaled model ice and full-scale sea ice is also assessed.
\end{abstract}

Keywords: Double-acting vessel; numerical model; icebreaking capability; ship maneuverability; ice model test

\section{Introduction}

Since the beginning of the 1990s, the major development of ice-going ships has been the use of podded propellers in ice with double-acting vessels (Jones, 2004). The idea is to design an efficient icebreaking stern for the vessel while keeping an efficient open-water bow. During these years a number of vessels have been designed and built according to the double-acting principle. Vocke et al. (2011) presented a recent review of the experiences gained from realized projects where the most relevant milestones in double-acting vessel developments were summarized. These vessels were first tested and studied in the ice model basin to get the best possible design features. Many operational experiences have also been gained through full-scale ice trials and practical operations of the vessels. Von
Bock und Polach et al. (2014a) presented a decisionbased design method for ships operating in open water and in ice, where the necessity to include and develop novel simulation-based methods for reliable assessment of ice-capable vessels was discussed.

The double-acting principle is of interest to the offshore industry as the oil and gas explorations are moving further north. In collaboration with several research institutes and companies, MARINTEK recently completed a project to develop a vessel (the CIVArctic vessel) for all-year intervention work on subsea oil and gas installations in the northeastern part of the Barents Sea. As the vessel will be operating and transiting in open waters for most of its working time, the design focus was initially on open-water performance. An efficient icebreaking stern was then designed for operation 
in moderate first-year level ice. A series of open-water and ice model tests have been carried out to verify this design (Berg et al., 2013).

In this paper, the main design considerations for the CIVArctic vessel is discussed along with the open water and ice model tests carried out to verify it. A numerical model is applied to evaluate the vessel's performance in level ice. The icebreaking capability and maneuverability in level ice are analyzed by evaluating the behavior of the vessel when it is running both ahead and astern. The paper also presents the implementation of a random crack size model for more realistic icebreaking behavior, giving more consistent evaluation of the ship's performance in various ice conditions. The numerical simulations are firstly conducted in model-scale for a direct comparison with the test results. The scaling of ship speed and ice resistance is then discussed by comparing the simulation results in both full-scale and model-scale. The effect on the vessel's performance of the different properties of scaled model ice and fullscale sea ice is also assessed.

\section{Vessel Design}

The double acting principle was applied in the design of the CIVArctic vessel. As the vessel for most of its working time will be operating in open waters, the design focus was initially on open water performance. An efficient icebreaking stern was then designed for operating in moderate first year level ice. Incorporated in the design was also high focus on safe effective work environment in cold climate through fully enclosed module handling tower and storage space for modules (as shown in Figure 1).

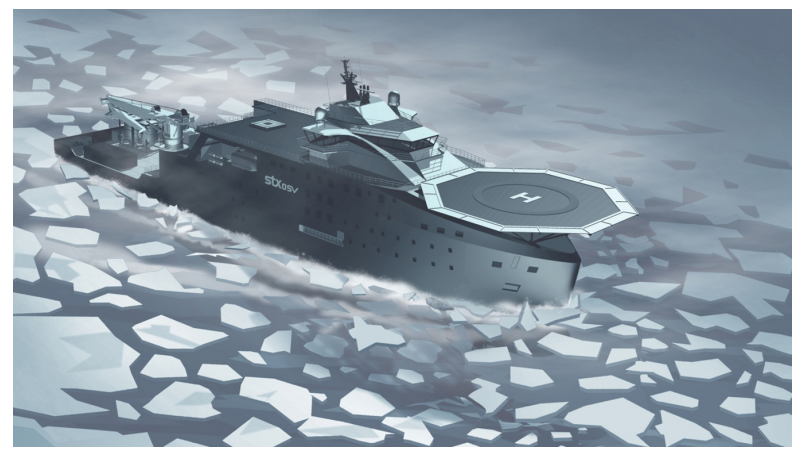

Figure 1: An illustration of the CIVArctic vessel (Source: http://www.sintef.no/Projectweb/ CIV-Arctic)

Among the parameters, tools and methods that have been considered along the iterative process of designing the CIVArctic vessel are (Berg et al., 2011):
- Open water performance indicators: Calm water performance, seakeeping performance, DP capability.

- Ice operation indicators: Level ice breaking capability, ship maneuvering capability (turning circle), ice loading in stationkeeping (in broken ice), DP-ice capability (Su et al., 2013).

- Model tests:

- MARINTEK towing tank, original design: Calm water performance and simplified seakeeping tests. Conducted in December 2009.

- MARINTEK ocean basin, modified design: Seakeeping and speed loss, stationkeeping. Conducted in November 2010.

- MARINTEK towing tank, modified design: Calm water performance. Conducted in January 2011.

- Aker Arctic ice tank, modified design: Ice operation. Conducted in May 2011.

- Numerical studies:

- CFD for open water resistance.

- VERES ShipX for open water motion characteristics.

- Numerical modelling (Su et al., 2012) for level ice performance.

The main dimensions of the CIVArctic vessel are shown in Table 1. The main propulsion mechanism is composed of two azimuthing propulsors each of $5 \mathrm{MW}$. Propeller blades are reinforced for ice milling. In addition the vessel has two retractable thrusters and two tunnel thrusters in the foreship.

\section{Ice model test}

To evaluate the vessel's ice performance, a series of model experiments were carried out in the Aker Arctic ice basin during May 2011 (Leiviskä, 2011). The main parameters of the ice basin are given in Table 2 (Wilkman et al., 2010). The tests included three days of forward ice-going performance, one day of ice maneuvering (see Figure 2), and three days of stationkeeping in ice. The vessel model, having a scale of $1: 24$, was equipped with azipod units and MARINTEK stock propellers.

The forward ice-going performance tests were conducted in three different level ice sheets $(0.5 \mathrm{~m}, 0.8 \mathrm{~m}$, and $1.2 \mathrm{~m}$ full-scale) using a constant rate of propeller revolutions. The model was free to move in all degrees of freedom except sway and yaw. On each test day, 
Table 1: Main dimensions of the CIVArctic vessel

\begin{tabular}{lrr}
\hline Parameters & Full-scale Value & Model-scale Value \\
\hline Length overall & $121.8 \mathrm{~m}$ & $5.0 \mathrm{~m}$ \\
Length between perpendiculars & $109.3 \mathrm{~m}$ & $4.5 \mathrm{~m}$ \\
Breadth moulded & $24.0 \mathrm{~m}$ & $1.0 \mathrm{~m}$ \\
Depth of main deck & $10.5 \mathrm{~m}$ & $0.43 \mathrm{~m}$ \\
Maximum scantling draught midship & $8.0 \mathrm{~m}$ & $0.33 \mathrm{~m}$ \\
Design draught & $6.5 \mathrm{~m}$ & $0.27 \mathrm{~m}$ \\
\hline
\end{tabular}

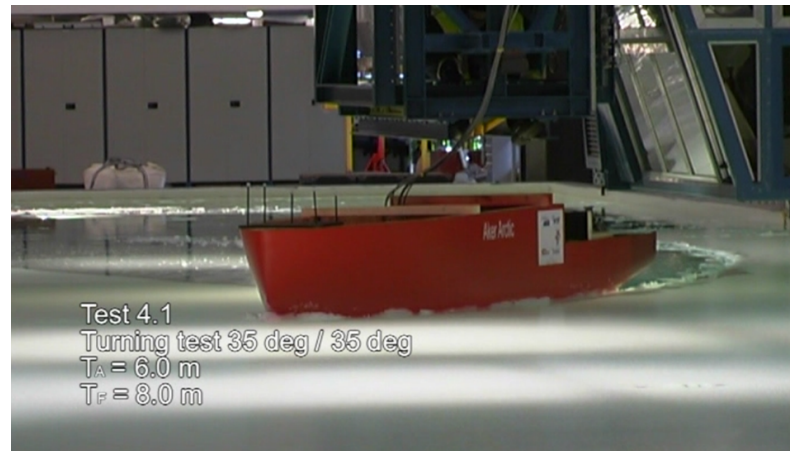

Figure 2: An example of the maneuvering tests in level ice (Source: Aker Arctic model test, Leiviskä (2011))

Table 2: Main parameters of the Aker Arctic ice basin (Wilkman et al., 2010).

\begin{tabular}{lr}
\hline Parameters & Value \\
\hline Length & $75 m$ \\
Width & $8 m$ \\
Water depth & $2.1-2.2 m$ \\
Water volume & $1300 \mathrm{~m}^{3}$ \\
\hline
\end{tabular}

floe ice and ridge tests followed the level ice experiments, where the performance in each ice regime was tested running both ahead and astern. Draft and trim were adjusted to acquire the best possible performance $\left(T_{F}=8.0 \mathrm{~m}\right.$ and $\left.T_{A}=6.0 \mathrm{~m}\right)$.

The maneuvering tests were conducted running ahead with constant propulsion power. For the turning circle evaluation the azipod units were turned to the target angles, and the vessel was allowed to turn. Three different azimuth angles were applied $\left(15^{\circ}, 35^{\circ}\right.$, and $55^{\circ}$ ) using both $100 \%$ and $120 \%$ propulsion power. It should be emphasized that the ice basin is too narrow to complete each turning circle; thus, the test results are only indicative.

The purpose of the stationkeeping experiments was to acquire an indication of the load levels associated with the operational ice conditions. This was obtained by towing the completely fixed vessel through stationary managed broken ice-fields with constant velocity. Such a setup simulates drifting ice, where the ice load time-series is recorded by a load cell in the connection point between the vessel and the towing carriage. Four different relative ice drift directions were applied $\left(0^{\circ}\right.$, $5^{\circ}, 10^{\circ}$, and $20^{\circ}$ ) in both $90 \%$ and $100 \%$ ice concentrations.

The experimental data on forward ice-going performance and stationkeeping have been applied in Su et al. (2012, 2013, 2014) and Kjerstad et al. (2013), respectively, to investigate the icebreaking and DP-ice capability of the CIVArctic vessel. This paper is a summary of the numerical studies of the ice-going performance and the comparison with corresponding experimental results.

\section{Numerical model}

The ice forces encountered by a ship transiting level ice depend primarily on the icebreaking and displacement processes. First the ice sheet touches the hull, and crushing occurs. This load will increase with the contact area until the ice sheet fails some distance away from the interaction zone. The failure mechanisms are 
mainly governed by the interaction geometry and ice material properties involved. For inclined planes, this usually means a bending failure. After the ice floe has been broken from the ice sheet, the advancing ship forces it to rotate, submerge, and slide along the hull. In some hull zones, typically at the shoulders and midship with large slope angles, crushing may be the only failure mode. A relative heading towards the ice sheet heavily exposing these hull sections will cause enlarged resistance.

Relevant examples of research on numerical modeling of ice-hull interaction and ship maneuvering in level ice can be found in Valanto et al. (2001); Liu et al. (2006); Martio (2007); Nguyen et al. (2009); Sawamura et al. (2010); Lubbad and Løset (2011); Tan et al. (2013), and Metrikin et al. (2013). In this paper, the partly validated empirical numerical model presented in Su et al. (2010a) is applied to investigate the icebreaking capability and maneuverability of the CIVArctic vessel in level ice. A 2D simulation program has been developed to reproduce the observed icebreaking patterns and the continuous icebreaking forces imposed by a level ice sheet, where the ice has uniform or randomly varying thickness and strength properties. The numerical method for the realization of the physical process of icebreaking can be found in $\mathrm{Su}$ et al. (2010a, 2011), while the simulation of ship maneuvering is mainly described herein.

\subsection{Equations of ship's motion}

Figure 3 illustrates the numerical ice-hull interaction model, which enables simulations of ice maneuvering by solving the three-degrees-of-freedom differential motion equations for surge, sway, and yaw:

$$
(\mathbf{M}+\mathbf{A}) \cdot \ddot{\mathbf{x}}(t)+\mathbf{B} \cdot \dot{\mathbf{x}}(t)+\mathbf{C} \cdot \mathbf{x}(t)=\mathbf{F}(t)
$$

where $\mathbf{M}, \mathbf{A}, \mathbf{B}$, and $\mathbf{C}$ are the rigid body mass, added mass, damping, and restoring force matrices, $\mathbf{x}=\left[\begin{array}{lll}x & y & \psi\end{array}\right]^{\mathrm{T}}$ is the displacement vector (surge, sway, and yaw) expressed as a function of time $t$, $\dot{\mathbf{x}}$ and $\ddot{\mathbf{x}}$ are, respectively, the first and second time derivatives of $\mathbf{x}$ (velocity and acceleration), and $\mathbf{F}=\left[\begin{array}{lll}F_{x} & F_{y} & M_{z}\end{array}\right]^{\mathrm{T}}$ is the force/moment vector.

The added mass and damping matrices are calculated in open water without considering the effect of ice. The contributions from wind and waves are neglected as minor forces to the ice load.

\subsection{Force decomposition}

In order to evaluate the forces encountered by a ship transiting in level ice, one of the basic assumptions that have commonly been accepted is that the total ice resistance can be taken as the superposition of several force

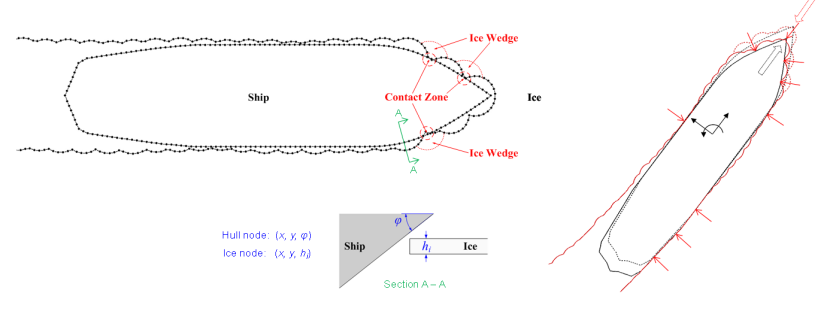

Figure 3: Illustration of the numerical ice-hull interaction model (Su et al., 2010a)

components, that is, icebreaking force, ice floe rotation and submergence force, and friction force associated with ice contact. However, this assumption is questionable since the force components could be "complicatedly entangled in each other" (Enkvist et al., 1979). Moreover, since open-water resistance is usually very small compared to ice resistance at icebreaking speeds, the coupling between them could be neglected without causing significant errors. Thus, we assume that the open-water resistance and the pure ice resistance are also separable (as described in Riska et al. (1997)).

Based on this superposition principle, the force/moment vector is then decomposed as:

$$
\mathbf{F}=\mathbf{F}_{p}+\mathbf{F}_{b r k}+\mathbf{F}_{s b m g}+\mathbf{F}_{\text {ow }}+\mathbf{F}_{\text {Euler }}
$$

where $\mathbf{F}_{p}$ is the propulsion force, $\mathbf{F}_{b r k}$ is the icebreaking force, $\mathbf{F}_{\text {sbmg }}$ is the ice forces induced during the displacement process (i.e., rotating, submerging, and sliding of the broken ice pieces), $\mathbf{F}_{\text {ow }}$ is the open water force, and $\mathbf{F}_{\text {Euler }}$ is a fictitious force (i.e., the Coriolis and centripetal force) induced by a non-uniformly rotating frame (i.e., the body-fixed frame) relative to the inertial frame.

Since the focus of this numerical model is on the icebreaking process, the icebreaking force $\mathbf{F}_{b r k}$, which is the immediate cause of the formation of the icebreaking pattern, is calculated by simulating the continuous icebreaking patterns and integrating the local icebreaking forces along the waterline (as shown in Figure 3), while other force components are estimated by some well-proven theoretical or semi-empirical formulas. For example, the open water force $\mathbf{F}_{\text {ow }}$ is calculated by the crossflow theory given in Faltinsen (1993), $\mathbf{F}_{\text {sbmg }}$ is calculated by following the force superposition principle given in Lindqvist (1989).

The propulsion forces are applied to the vessel by using the thrust curves determined from model tests. It should be emphasized that only the two main stern propulsors are considered in the level-ice performance analysis of the CIVArctic vessel. Different thrust curves are given in Leiviskä (2011) when the vessel is running ahead and astern. It is found that there is a re- 
duction of net thrust when the vessel is running astern. In that case the ice resistance is also reduced due to the flushing effect of the propeller jet which reduces the friction between the ship hull and ice. When running astern the propeller accelerates the water, which also makes the breaking of the ice easier (Vocke et al., 2011). The focus of this numerical model is on ice-hull interaction. Neither propeller jet nor propeller-ice interaction is included. The thrust deduction is taken into account by using the different ahead and astern thrust curves obtained in the open-water model tests. The flushing effect is simply accounted for by modifying the hull surface area covered by underwater broken ice pieces, which is based on the Lindqvist's (Lindqvist, 1989) formula of submerging and sliding ice resistance. This simplified method was introduced in Su (2012) and further discussed in Tan (2014) by comparing with the corresponding model test results.

\subsection{Numerical integration}

A step-by-step numerical integration method is applied to solve the equations of the ship's motion. According to Newmark's method (Newmark, 1959), the general integral equations are:

$$
\begin{aligned}
\dot{\mathbf{x}}\left(t_{k+1}\right)= & \dot{\mathbf{x}}\left(t_{k}\right)+(1-\lambda) \cdot \ddot{\mathbf{x}}\left(t_{k}\right) \cdot \Delta t \\
& +\lambda \cdot \ddot{\mathbf{x}}\left(t_{k+1}\right) \cdot \Delta t \\
\mathbf{x}\left(t_{k+1}\right)= & \mathbf{x}\left(t_{k}\right)+\dot{\mathbf{x}}\left(t_{k}\right) \cdot \Delta t+\left(\frac{1}{2}-\beta\right) \cdot \ddot{\mathbf{x}}\left(t_{k}\right) \cdot \Delta t^{2} \\
& +\beta \cdot \ddot{\mathbf{x}}\left(t_{k+1}\right) \cdot \Delta t^{2}
\end{aligned}
$$

These equations are obtained by a Taylor-series expansion in which the residual term is approximated by the quadrature formula. The weighting terms $\lambda$ and $\beta$ are free parameters in the quadrature formula that are determined by the requirements related to stability and accuracy. If a linear acceleration is assumed within the time interval $\Delta t$, we choose $\lambda=\frac{1}{2}$ and $\beta=\frac{1}{6}$, and equation (3) becomes:

$$
\begin{aligned}
\dot{\mathbf{x}}\left(t_{k+1}\right)= & \dot{\mathbf{x}}\left(t_{k}\right)+\frac{1}{2} \ddot{\mathbf{x}}\left(t_{k}\right) \cdot \Delta t \\
& +\frac{1}{2} \ddot{\mathbf{x}}\left(t_{k+1}\right) \cdot \Delta t \\
\mathbf{x}\left(t_{k+1}\right)= & \mathbf{x}\left(t_{k}\right)+\dot{\mathbf{x}}\left(t_{k}\right) \cdot \Delta t+\frac{1}{3} \ddot{\mathbf{x}}\left(t_{k}\right) \cdot \Delta t^{2} \\
& +\frac{1}{6} \ddot{\mathbf{x}}\left(t_{k+1}\right) \cdot \Delta t^{2}
\end{aligned}
$$

where

$$
\begin{aligned}
\ddot{\mathbf{x}}\left(t_{k+1}\right)= & (\mathbf{M}+\mathbf{A})^{-1}\left(\mathbf{F}\left(t_{k+1}\right)-\mathbf{B} \cdot \dot{\mathbf{x}}\left(t_{k+1}\right)\right. \\
& \left.-\mathbf{C} \cdot \mathbf{x}\left(t_{k+1}\right)\right)
\end{aligned}
$$

This is a popular method resulting in continuity in the acceleration, velocity, and displacement. By inserting equation (5) into equation (4), we get the explicit form:

$$
\begin{aligned}
\mathbf{x}\left(t_{k+1}\right)= & \left(\frac{6}{\Delta t^{2}}(\mathbf{M}+\mathbf{A})+\frac{3}{\Delta t} \mathbf{B}+\mathbf{C}\right)^{-1} \\
& \cdot\left(\mathbf{F}\left(t_{k+1}\right)+(\mathbf{M}+\mathbf{A}) \cdot \mathbf{a}_{k}+\mathbf{B} \cdot \mathbf{b}_{k}\right)
\end{aligned}
$$

where

$$
\begin{aligned}
& \mathbf{a}_{k}=\frac{6}{\Delta t^{2}} \mathbf{x}\left(t_{k}\right)+\frac{6}{\Delta t} \dot{\mathbf{x}}\left(t_{k}\right)+2 \ddot{\mathbf{x}}\left(t_{k}\right) \\
& \mathbf{b}_{k}=\frac{3}{\Delta t} \mathbf{x}\left(t_{k}\right)+2 \dot{\mathbf{x}}\left(t_{k}\right)+\frac{1}{2} \ddot{\mathbf{x}}\left(t_{k}\right) \cdot \Delta t
\end{aligned}
$$

\subsection{Iteration and convergence criteria}

As shown in equation (6), the force/moment vector at time step $k+1$, that is, $\mathbf{F}\left(t_{k+1}\right)$, is unknown at time step $k$ due to the interdependence between the ice loads and the ship's motion. Thus, iterations are performed at each time step until an acceptable accuracy is achieved. Herein, the convergence criterion is based on the variation of the force/moment vector from iteration step $i$ to iteration step $i+1$, given by:

$$
\frac{\left|\mathbf{F}\left(t_{k+1}\right)_{i+1}-\right| \mathbf{F}\left(t_{k+1}\right)_{i} \mid}{\left|\mathbf{F}\left(t_{k+1}\right)_{i}\right|}<\varepsilon
$$

where $\varepsilon$ is a small, positive number of the order of $10^{-3}$.

The above numerical procedure is implemented into a FORTRAN program, which is illustrated by the flowchart given in Figure 4. At each time step, the force vector is firstly assumed to be the same as in the previous step. It is then updated by solving the equations of the ship's motion and integrating the local contact forces between the ice and hull. If the updated force vector satisfies the convergence criterion defined in equation (8), it will be accepted as the final solution for the present time step. Otherwise it will be used to resolve the equations of the ship's motion and to recalculate the contact forces between the ice and hull. The purpose of introducing this iterative procedure is to find a balance between the penetration of the vessel into ice and the resulting ice forces. It can be expected that the broken ice channel formed at one moment will have a cumulative effect on the following icebreaking process, especially during ship maneuvering (Su et al., 2010b). Thus, the continuous icebreaking process can be more correctly reproduced by applying an iterative procedure for the determination of the ice load and ship's motion at each time step. 


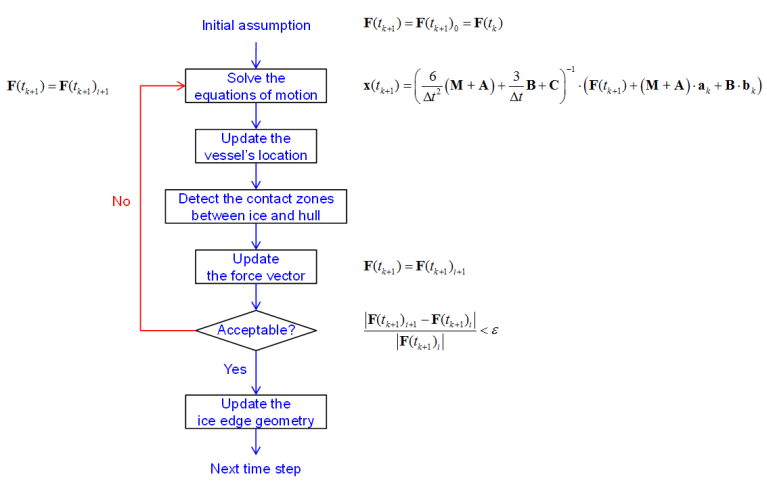

Figure 4: Flow chart of the numerical procedure.

\section{Icebreaking patterns}

The normal open water draft for the CIVArctic vessel is $T_{F}=T_{A}=6.5 \mathrm{~m}$, the ice draft is $T_{F}=8.0 \mathrm{~m}$, and $T_{A}=6.0 \mathrm{~m}$ (draft and trim were adjusted in the ice model test to obtain the best possible ice performance). Figure 5 features the icebreaking waterline of the CIVArctic vessel. Compared to a typical icebreaker, the CIVArctic vessel has three additional icebreaking components: the bulbous bow and the two headboxes of the azimuth propulsors at the stern. As shown in Figures 6 and 7, when the vessel is running ahead, the bulbous bow can break the ice upwards; when the vessel is running astern the headboxes can break the ice downwards. Therefore, the bulbous bow and the headboxes are modeled separately and the simulated icebreaking patterns have been compared with the experimental results (Leiviskä, 2011).

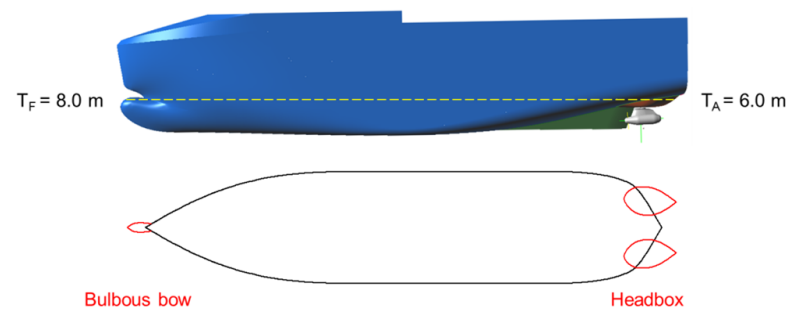

Figure 5: Icebreaking waterline of the CIVArctic vessel (double-acting vessel).
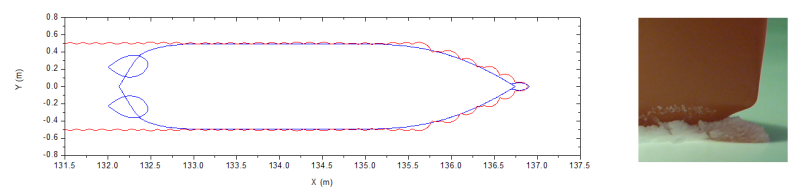

Figure 6: Icebreaking pattern around the bulbous bow in $22 \mathrm{~mm}$ (0.53m full-scale) level ice.

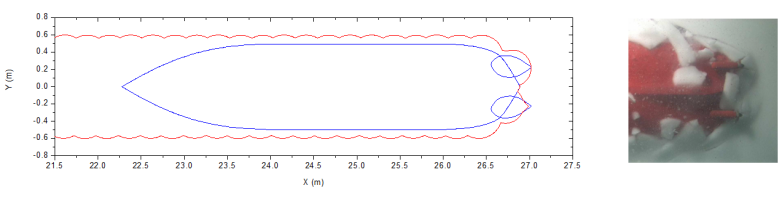

Figure 7: Icebreaking pattern around the headbox in $52 \mathrm{~mm}$ (1.26m full-scale) level ice.

\section{Deterministic crack size}

In this study, the icebreaking pattern is firstly assumed to be determined by the characteristic length of ice, ship speed, and the frame angle around the hull. The bending crack is approximated by a circular arc and the crack radius is calculated by a deterministic expression given in Wang (2001) (based on information from Enkvist (1972) and Varsta (1983)). It should be emphasized that the deterministic crack size does not mean the crack size is constant; it changes with the ice condition and ship's motion, but no random variation is included.

Random crack size

It is found in the model test that the ice is frequently crushed at the stem (with the bulb) when the vessel is running ahead. Sometimes bending failure also happens (as shown in Figure 8) and cracks of various sizes are observed in an icebreaking run (as shown in Figure 9 ). To the best of the author's knowledge, there is no reliable theory on the probabilistic distribution of the crack size during continuous icebreaking.



Figure 8: Screenshots from an icebreaking run in ice basin, running ahead in $22 \mathrm{~mm}$ (0.53m fullscale) level ice.

McKindra and Lutton (1981) analyzed the broken ice dimensions generated during the 1978-1979 winter ice trials of the U.S. Coast Guard 140-ft WTGB icebreaker. The hypothesis for this study was that the ice size distribution was log-normal. Tatinclaux (1986) also used the log-normal distribution on the floe size observed in the model tests of a wedge-shaped bow. In a numerical simulation of ice-cone interaction, Izumiyama et al. (1992) assumed that the crack size followed a normal distribution. As shown in Figure 10, the size of the crack is defined by the radius $R$ of the approximated circular arc and the ratio $Z$ of the crack 

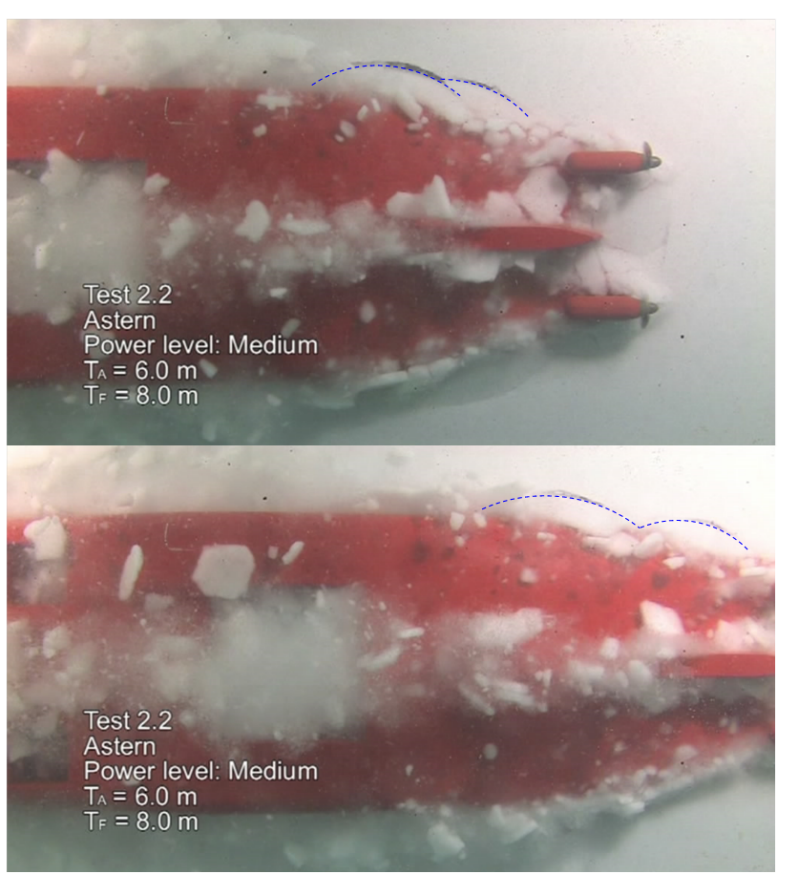

Figure 9: Screenshots from an icebreaking run in ice basin, running astern in $33 \mathrm{~mm}(0.80 \mathrm{~m}$ fullscale) level ice.

radius to the length $l_{b r}$, given by:

$$
l_{b r}=\left(\sigma_{u} h / \gamma\right)^{0.5}
$$

where $\sigma_{u}$ is the flexural strength of ice in upward bending, $h$ is the ice thickness, and $\gamma$ is the specific weight of water. The distribution has a mean $Z_{m}$ of 0.94 and a standard deviation $Z_{s d}$ of 0.27 which were determined based on the observed crack pattern in the model test. Izumiyama et al. (1992) gave no definite reason for the selection of normal distribution in this study. However, it was a reasonable estimate based on the experimental data.

In the present simulation, the crack size is defined by a random crack radius. There have been no reliable theory on the crack size distribution, and the available experimental data are not sufficient for a statistical analysis. Therefore, a normal distribution is used and the ratio between the standard deviation $R_{s d}$ and the mean crack radius $R_{m}$ is assumed to be the same as that shown in Figure $10\left(Z_{s d} / Z_{m}\right)$. Herein, the mean crack radius is calculated by the deterministic method mentioned above (detailed expression can be found in Su et al. (2010a)). A random crack radius can then be generated by using:

$$
\begin{aligned}
F(R) & =\frac{1}{\sqrt{2 \pi \cdot R_{s d}}} \cdot \int_{0}^{R} \exp \left(\frac{-\left(s-R_{m}\right)^{2}}{2 R_{s d}{ }^{2}}\right) \cdot d s \\
U & \sim U(0,1) \\
R & =F^{-1}(U)
\end{aligned}
$$

where $F(R)$ is the cumulative distribution function (CDF) of the crack radius, $F^{-1}(U)$ is the inverse CDF, and $U$ is a randomly generated number between 0 and 1.

Figure 11 shows an example of the simulated icebreaking pattern with randomly generated crack sizes. In general, the numerical simulation is comparable to the experimental result, though the assumed circular crack can not capture all details of the observed icebreaking pattern. Differences do exist if we look at the instantaneous crack patterns. However, it is still a reasonable assumption for simulating the continuous icebreaking process and the ship's overall performance.

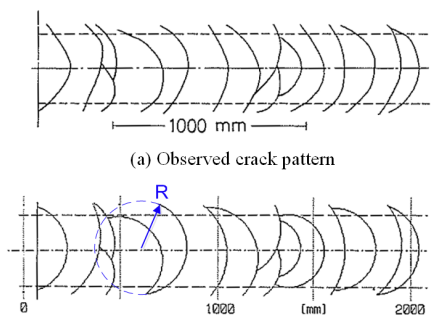

(b) Approximated crack pattern

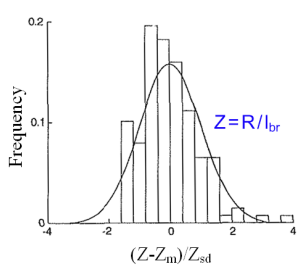

(c) Crack size distribution
Figure 10: An example of the observed and approximated crack size distributions in the model test of ice-cone interaction (Courtesy: Izumiyama et al. (1992)).

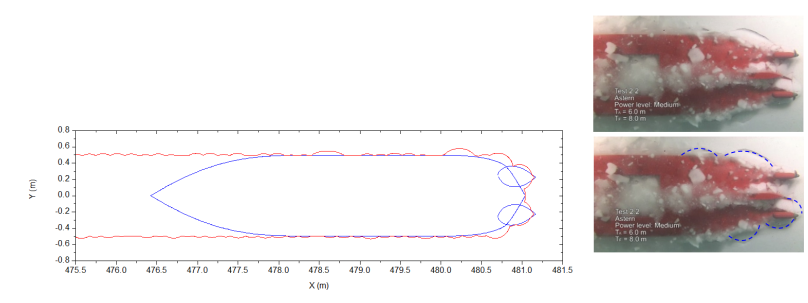

Figure 11: Simulated and observed icebreaking patterns, running astern in $33 \mathrm{~mm}(0.80 \mathrm{~m}$ fullscale) level ice. 


\section{Icebreaking capability analysis}

The icebreaking capability is analyzed based on the experimental data and the simulated $h-\nu$ curve. This displays the speed $(\nu)$ that the vessel can attain in level ice as a function of the ice thickness $(h)$. For direct comparison between the experimental data and the numerical model, the simulations required to create an $h-\nu$ curve are conducted at model scale. The simulation results corresponding to deterministic and random crack sizes are then discussed.

\subsection{Deterministic crack size}

Figure 12 shows the $h-\nu$ curves obtained when the vessel is running straight ahead and astern with deterministic crack size. A quadratic regression line is fitted to the simulation results and evaluated against the speed value obtained from the ice model test. For the ahead $h-\nu$ curve, the single experimental data point fits the regression line nicely. As there is only one experimental data point, no regression line can be fitted to the experimental data for further investigation. The same procedure is applied to obtain the $h-\nu$ curve running astern, which is also featured in Figure 12. In this case, two experimental speed values are available, and they are evenly distributed on both sides of the fitted simulation data line. Due to the limited experimental data, no regression line is fitted to the experiment.

The simulation results generally agree with the design intention that the level-ice-breaking capacity of the vessel should be better running astern (maximum ice thickness: $50 \mathrm{~mm}$ ) than running ahead (maximum ice thickness: $24 \mathrm{~mm}$ ). When the ship is running ahead, as shown in Figure 13 (a-b), the ice is frequently crushed at the stem (with the bulb) without bending failure, which is associated with high loads. As the bulb and bow are designed for open-water operations, they are found to be unfavorable for performance in level ice. A reason for the superior stern ice-handling capacity is shown in Figure 13 (c), where the ship is running astern, in which case the headboxes of the stern propulsors will interact and break the ice mainly through bending failure.

Another finding from the numerical simulation is the presence of so-called shoulder crushing. The CIVArctic vessel is designed to have a vertical hull surface at the midship and a large slope angle (close to $90^{\circ}$ ) at the shoulder area. Therefore, the hull shoulder can not break the ice by bending, and shoulder crushing happens when the bow or the stern breaks a narrower channel than the ship beam. In this case the ship has to force itself to crush the rest of the channel width close to the ship beam, and the ice resistance is highly increased. As shown in Figure 13 (a), shoulder crushing

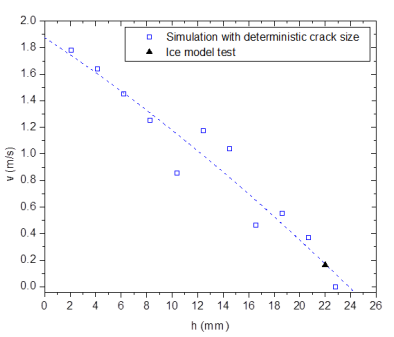

(a)

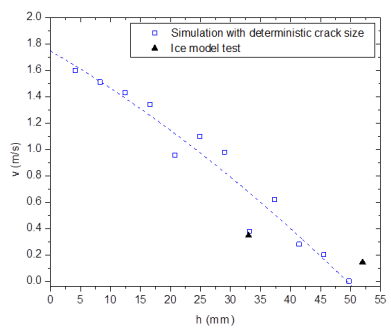

(b)
Figure 12: (a) $h-\nu$ curve obtained when the vessel is running ahead. (b) $h-\nu$ curve obtained when the vessel is running astern. All numbers are at model scale, and simulations are conducted with deterministic crack size.



(a)

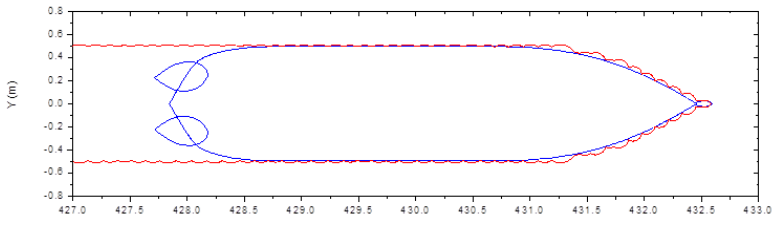

(b)

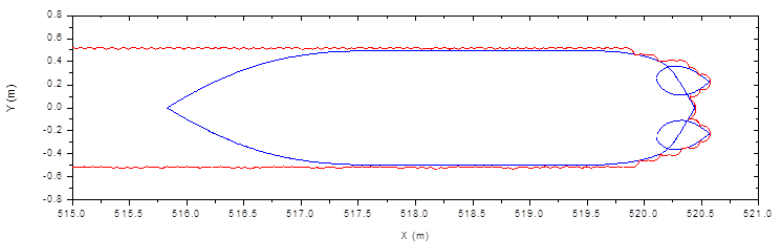

(c)

Figure 13: Examples of the simulated icebreaking runs with deterministic crack size. (a) Running ahead in $10.36 \mathrm{~mm}$ (0.25m full-scale) level ice, featuring consistent shoulder crushing. (b) Running ahead in $12.43 \mathrm{~mm}(0.30 \mathrm{~m}$ fullscale) level ice. (c) Running astern in $12.43 \mathrm{~mm}$ (0.30 $\mathrm{m}$ full-scale) level ice. 
consistently happens during the simulated icebreaking run in $10.36 \mathrm{~mm}$ (0.25m full-scale) level ice. Accordingly, the obtained speed of the ship is lower than in the cases without consistent shoulder crushing, even in the cases in which the ice is thicker (e.g., 12.43 and $14.50 \mathrm{~mm}$ as shown in Figure 12 (a)).

\subsection{Random crack size}

Figure 14 shows two examples of the simulated icebreaking runs with random crack size. Compared with Figure 13, an obvious time-variation of the crack pattern can be found during one icebreaking run (in a certain ice condition). But the variation from one ice condition to another is reduced if we look at the shoulder crushing effect. As shown in Figure 14, intermittent shoulder crushing is observed in both 10.36 and $12.43 \mathrm{~mm}$ ice, while Figure 13 shows consistent shoulder crushing in $10.36 \mathrm{~mm}$ ice but almost no shoulder crushing in $12.43 \mathrm{~mm}$ ice.

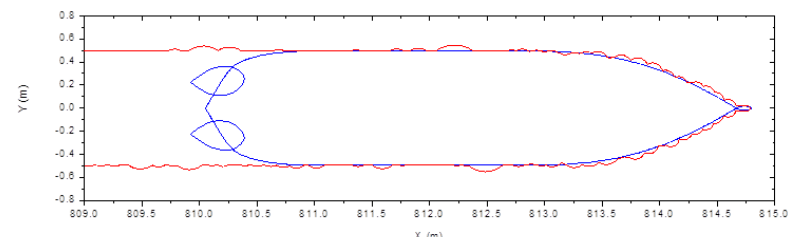

(a)

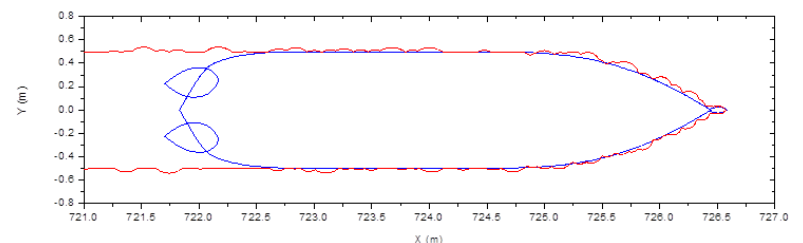

(b)

Figure 14: Examples of the simulated icebreaking runs with random crack size. (a) Running ahead in $10.36 \mathrm{~mm}$ (0.25m full-scale) level ice. (b) Running ahead in $12.43 \mathrm{~mm}(0.30 \mathrm{~m}$ fullscale) level ice.

Figure 15 shows a comparison of the simulated ice force (in surge direction) time-series in $12.43 \mathrm{~mm}$ ice. The blue line features the result in which the deterministic crack size is applied while the red line features the result in which the random crack size is applied. The difference between these two results reflects the shoulder crushing effect. It is found that the ice resistance in a short time period (see e.g. the time period from 191 to $192 s$ ) is increased by about $45 \%$ due to the occurrence of shoulder crushing. In general, the average ice resistance (from 100 to $300 s$ ) is increased by about $21 \%$, and this results in a $16 \%$ decrease of ship speed.
The simulated $h-\nu$ curves are compared in Figure 16. It is found that when the random crack size is applied the simulation results are more smoothly distributed along the fitted regression line. This is because the shoulder crushing happens in almost all ice conditions in a moderate manner. In general, by introducing a random variation of the crack size the numerical model will give a more consistent evaluation of the ship's performance in various ice conditions.

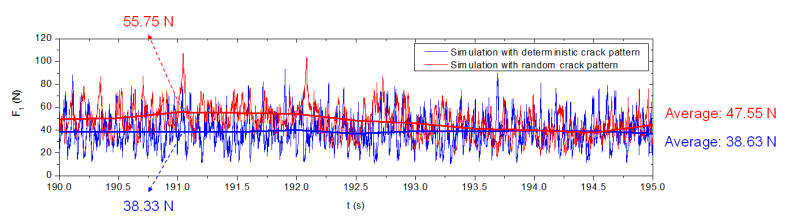

Figure 15: Comparison between the simulated ice force (in surge direction) time-series, running ahead in $12.43 \mathrm{~mm}(0.30 \mathrm{~m}$ full-scale) level ice with deterministic and random crack size.

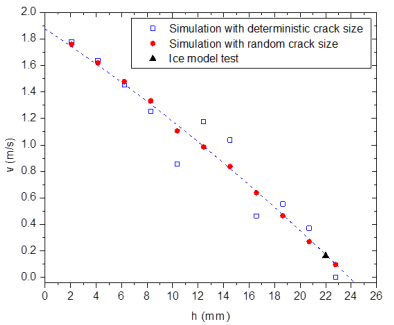

(a)

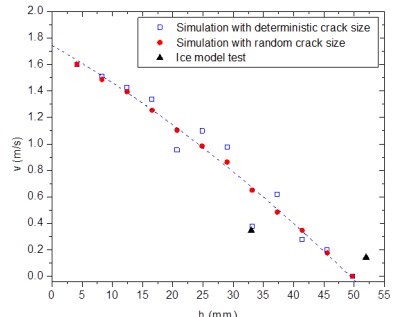

(b)
Figure 16: (a) $h-\nu$ curve obtained when the vessel is running ahead. (b) $h-\nu$ curve obtained when the vessel is running astern. All numbers are at model scale, and simulations are conducted with deterministic and random crack size.

\section{Maneuverability analysis}

The maneuverability of the CIVArctic vessel in level ice is analyzed based on the experimental data and the simulated turning circles. The simulations required to evaluate the turning circle diameters are conducted at model scale and the random crack size is applied. The turning performance is then measured by the turning circle diameter $\left(D_{t}\right)$ divided by the ship length $(L)$.

During the turning tests conducted in the Aker Arctic ice basin, three different propulsion azimuth angles were applied $\left(15^{\circ}, 35^{\circ}\right.$, and $\left.55^{\circ}\right)$, and $120 \%$ power was used in all cases but one, where $100 \%$ was used. The 
reason for the high power level was that the vessel was already struggling when approaching directly ahead in the $19.7 \mathrm{~mm}(0.5 \mathrm{~m}$ full-scale) level ice sheet used for the turning tests. Figure 17 shows the setup of each test and the measured turning tracks. Since the Aker Arctic ice basin is too narrow to complete each turning circle, the turning diameter was roughly estimated by a circular regression of the measured turning tracks (Leiviskä, 2011).
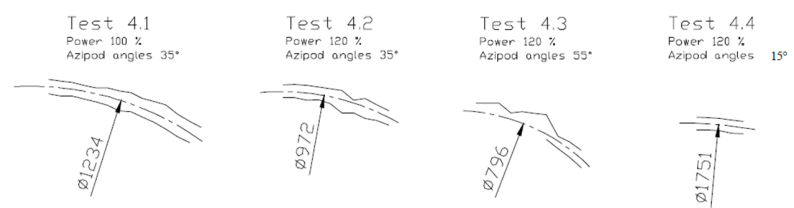

Figure 17: The measured tracks and estimated turning diameters from the model tests (Source: Aker Arctic model test, Leiviskä (2011)). All numbers are at full scale (in meters).

Figure 18 shows the simulated turning circle using $120 \%$ power and a propulsion azimuth angle of $35^{\circ}$. The vessel loses velocity when turning, and the simulated turning circle diameter is about $20 \mathrm{~L}$. This is much higher than the $5 L$ requirement for vessels that have to maneuver well in certain ice conditions. By increasing the propulsion azimuth to $55^{\circ}$, the vessel still does not turn well, and both model tests (Leiviskä, 2011) and previous simulation results have shown that the vessel can eventually get stuck in the ice (as shown in Figure 19).
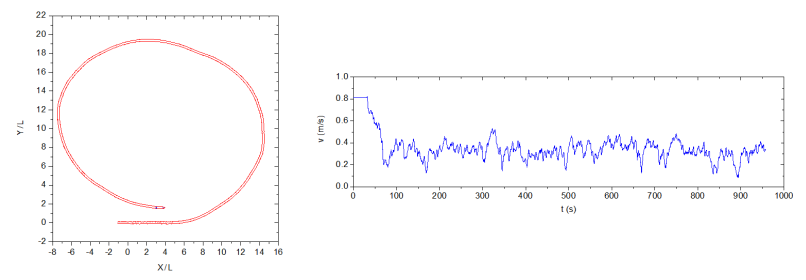

Figure 18: Simulated turning circle in $19.7 \mathrm{~mm}(0.5 \mathrm{~m}$ full-scale) level ice (power $120 \%$, azimuth angle $35^{\circ}$ ) with the corresponding velocity response. The turning circle is plotted with reference to ship length $L$.

As shown in Figure 20, an inward heel of the vessel was observed in the model tests and the estimated average heeling angle is around $2^{\circ}$. This is also considered in the numerical simulation. The changed icebreaking waterline and hull angles are determined from a threedimensional model of the vessel. Then Figure 21 shows the comparison between the numerical simulation and experimental results, where the blue dashed line indicates the $5 L$ requirement. A $2^{\circ}$ heeling angle and the
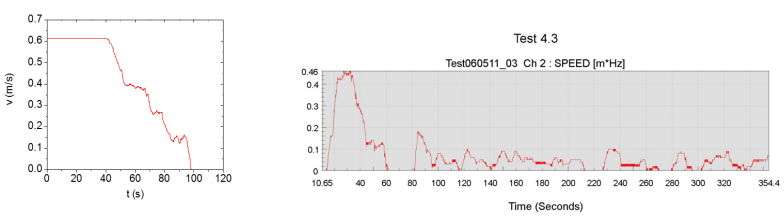

Figure 19: Simulated (left) and measured (right) velocity time-series in $19.7 \mathrm{~mm}$ ( $0.5 \mathrm{~m}$ full-scale) level ice (power 120\%, azimuth angle $55^{\circ}$ ).

different ice thicknesses are applied in the numerical simulations. However, the available experimental data are not sufficient for a meaningful comparison, because the heeling angle was not precisely measured and the ice basin was too narrow to complete each turning circle.

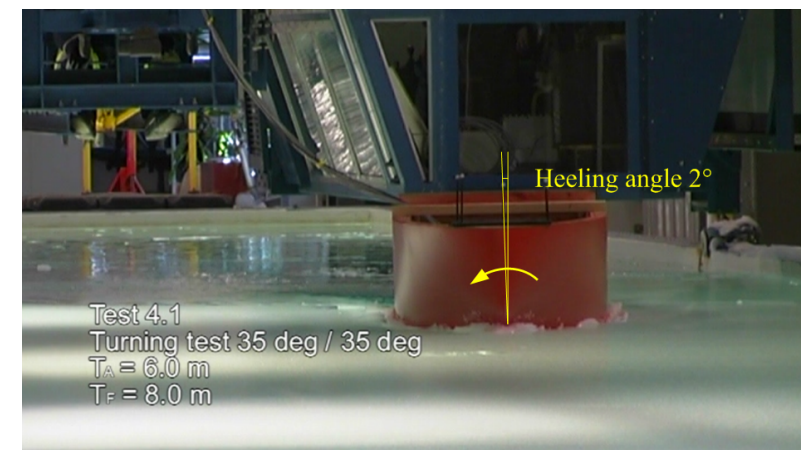

Figure 20: Estimated average heeling angle during the turning test.

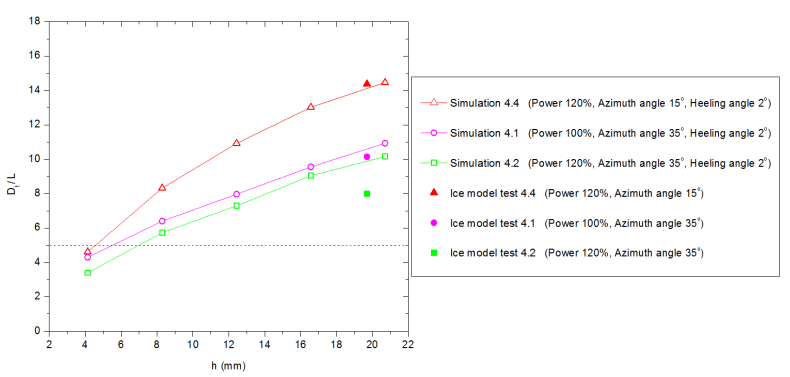

Figure 21: Comparison between the simulated turning circle diameters and the estimated values from the model tests. The turning circle diameter $D_{t}$ is divided by ship length $L$. All numbers are at model scale.

A parameter study of the heeling angle is then shown in Figure 22. On average the turning circle diameter is reduced by about $65 \%$ when a $3^{\circ}$ heeling angle is applied. This conclusion is based on a numerical study with a specific hull form. As shown in Figure 23, the inward heel of the vessel makes its port side break ice 
in a more favorable way. As mentioned before, the CIVArctic vessel has a vertical hull surface at the midship which can not break the ice by bending when the vessel is upright. By heeling the vessel, large bending cracks are created at the midship and aft shoulder areas, resulting in a better turning performance. However, the conclusions may be different if the hull forms are different. For example, during the field trials of the icebreaker Tor Viking II (Riska et al., 2001), it was found that when a $3^{\circ}$ heeling angle was applied, the turning circle diameter of the vessel was only reduced by about $42 \%$ (in $0.6 \mathrm{~m}$ level ice).

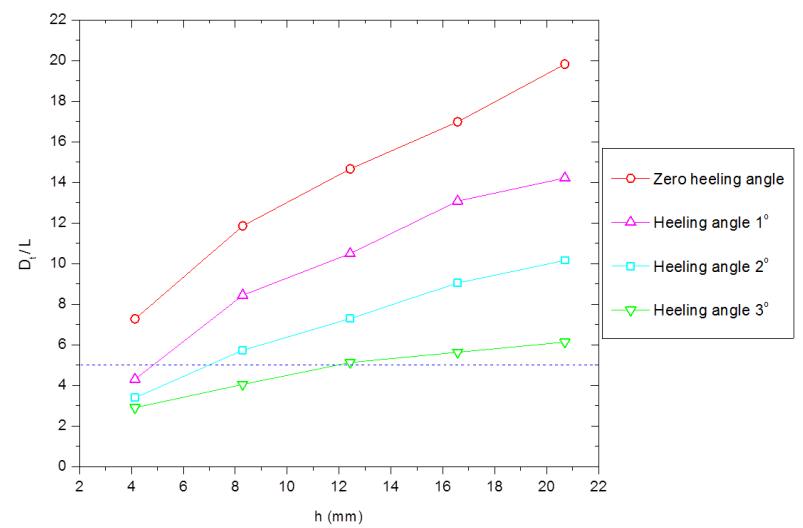

Figure 22: Simulated turning circle diameters in different ice conditions (power 120\%, azimuth angle $\left.35^{\circ}\right)$. The turning circle diameter $D_{t}$ is divided by ship length $L$. All numbers are at model scale.

Figure 24 shows also a simulated turning circle when the CIVArctic vessel is running astern with zero heeling angle. It is found that the turning performance of the vessel is better when it is running astern than when it is running ahead, as shown in Figure 25, where the turning circle diameter is reduced by about $30 \%$ on average. This conclusion is solely based on the simulation results since no experimental data are available for comparison.

\section{Discussion}

In this section, the scaling of ice force and ship speed, and the sea ice performance of CIVArctic vessel are discussed based on the simulations conducted in both model-scale and full-scale.

\subsection{Scaling of Ice Force and Ship Speed}

All numerical results presented above are obtained from model-scale simulations, where the ice and ship
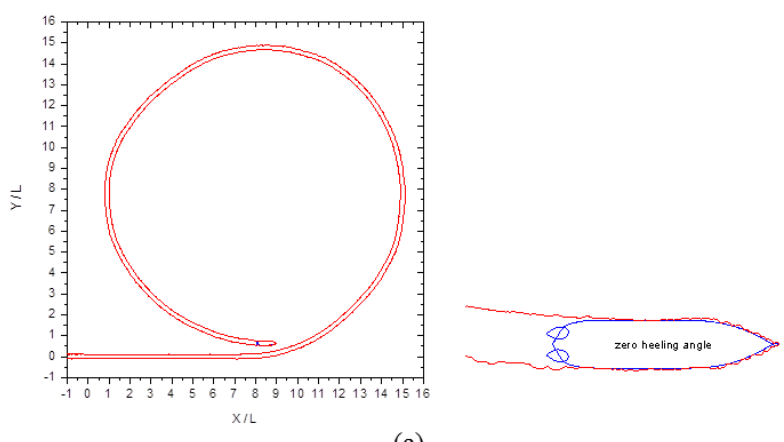

(a)
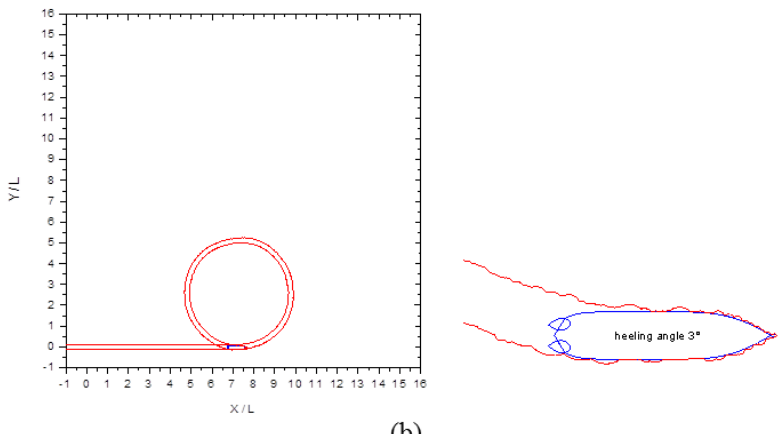

(b)

Figure 23: Simulated turning circles in $12.43 \mathrm{~mm}(0.3 \mathrm{~m}$ full-scale) level ice (power 120\%, azimuth angle $35^{\circ}$ ). (a) Zero heeling angle. (b) Heeling angle $3^{\circ}$. The turning circle is plotted with reference to ship length $L$.
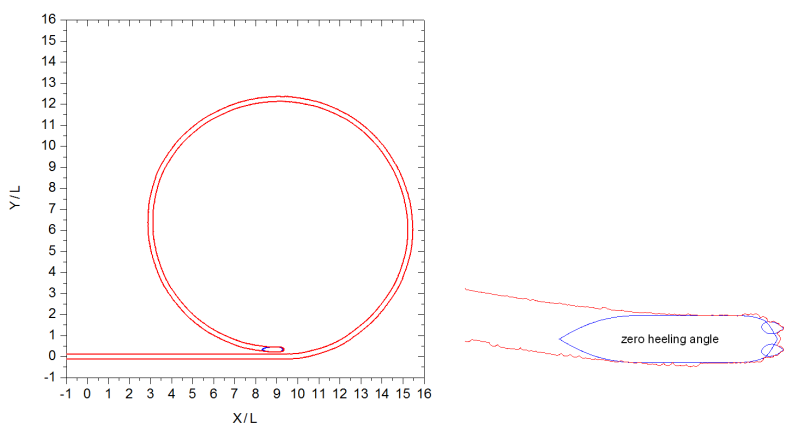

Figure 24: Simulated astern turning circle in $12.43 \mathrm{~mm}$ (0.3 $\mathrm{m}$ full-scale) level ice (power $120 \%$, azimuth angle $35^{\circ}$ ). The turning circle is plotted with reference to ship length $L$. 


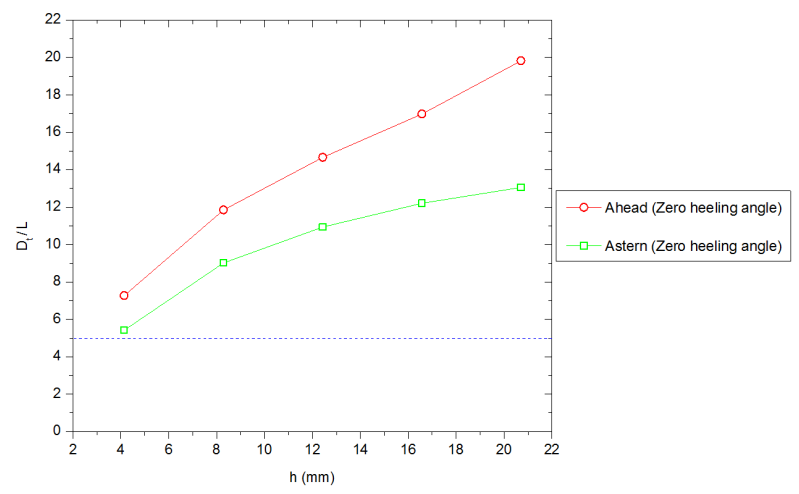

Figure 25: Comparison between the ahead and astern turning circles (power 120\%, azimuth angle $\left.35^{\circ}\right)$. The simulated turning circle diameter $D_{t}$ is divided by ship length $L$.

parameters are directly from the model tests. The fullscale simulations are carried out by considering the scaling laws shown in Table 3, where the geometric scale factor, $\lambda$, is equal to 24 . It should be noted that the scaled ice and ship parameters are used for the fullscale simulations, while the size effect on the fracture of a floating ice sheet (see e.g. Bazant and Guo (2002)) in model-scale and full-scale is not considered.

For a comparison, the model-scale ship speed and ice force values are firstly scaled and plotted in Figures. 26 and 27 by:

$$
\begin{aligned}
{[V]_{P} } & =\sqrt{\lambda} \cdot[V]_{M} \\
{\left[R_{i}\right]_{P} } & =\lambda^{3} \cdot\left[R_{i}\right]_{M}
\end{aligned}
$$

where $[V]_{P}$ is the speed value in full-scale, $[V]_{M}$ is the speed value in model-scale, $\left[R_{i}\right]_{P}$ is the resistance value in full-scale, and $\left[R_{i}\right]_{M}$ is the resistance value in model-scale.

The corresponding simulation results in full-scale are then plotted in Figures 26 and 27 too. As shown in these two figures, the fitted regression lines to the model-scale and full-scale results almost coincided with each other, though there is a significant deviation between each individual data point. This indicates that the theoretical scaling laws defined by Equations (11) and (12) can be generally applied for the scaling of simulated ship speed and ice forces, while a certain deviation value should be taken into account. One possible reason for this deviation is due to the variation of simulated icebreaking patterns, such as the occurrence of shoulder crushing. It can be expected that this deviation would be more considerable if the size effect on each individual icebreaking process is considered.

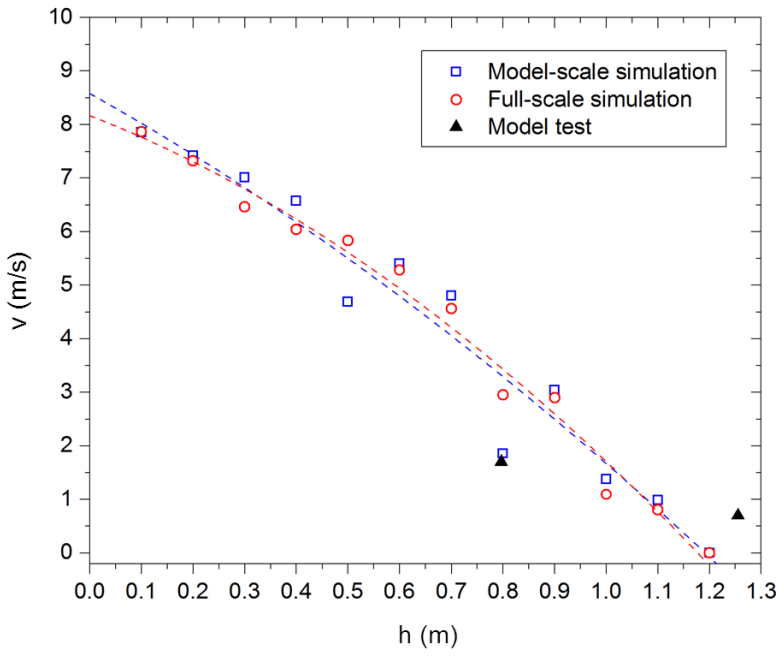

Figure 26: $h-\nu$ curve obtained when the vessel is running astern (the scaled model-scale simulation results and the full-scale simulation results with scaled ice and ship parameters)

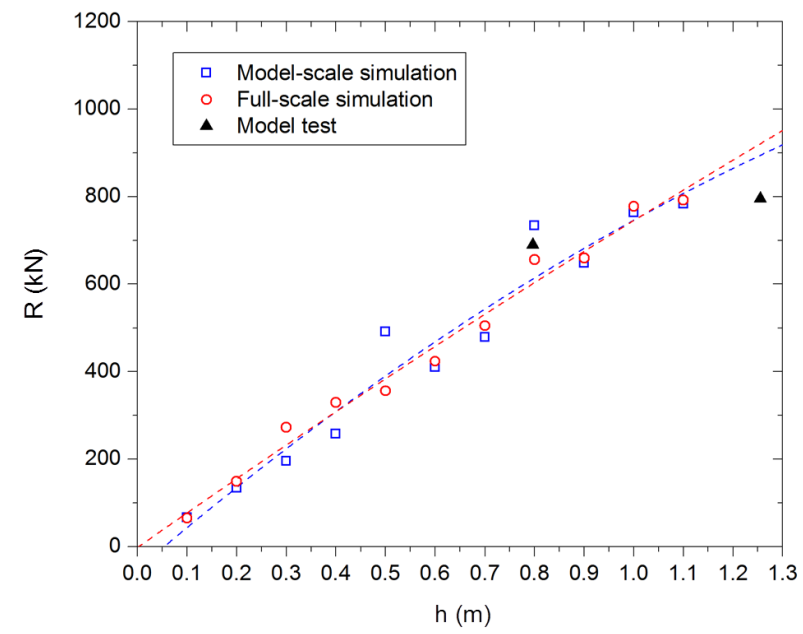

Figure 27: The ice resistance $R$ that the vessel encountered, running astern in the ice of increasing thickness $h$ (the scaled model-scale simulation results and the full-scale simulation results with scaled ice and ship parameters. 
$\mathrm{Su}$ et al., "Investigation of a double-acting vessel performance in level ice"

Table 3: Scaling of the input parameters for the full-scale simulation.

\begin{tabular}{lrrr}
\hline Parameters & Model-scale value & Scaling & Full-scale Value \\
\hline Elastic modulus & $17.26 \mathrm{MPa}$ & $\lambda$ & $416.62 \mathrm{MPa}$ \\
Flexural strength & $21.92 \mathrm{kPa}$ & $\lambda$ & $0.53 \mathrm{MPa}$ \\
Crushing strength & $43.84 \mathrm{kPa}$ & $\lambda$ & $1.06 \mathrm{MPa}$ \\
Density & $930 \mathrm{~kg} / \mathrm{m}^{3}$ & 1 & $930 \mathrm{~kg} / \mathrm{m}^{3}$ \\
Poisson's ratio & 0.33 & 1 & 0.33 \\
Frictional coefficient & 0.05 & 1 & 0.05 \\
Displacement & $0.91 t$ & $\lambda^{3}$ & $12865 t$ \\
Bollard pull & $7.47 \mathrm{~kg}$ & $\lambda^{3}$ & $105 t$ \\
\hline
\end{tabular}

Table 4: Modified ice properties for the evaluation of sea ice performance.

\begin{tabular}{lrrrr}
\hline Parameters & Modelice & Input 1 & Input 2 & Input 3 \\
\hline Elastic modulus & $416.62 \mathrm{MPa}$ & $3.0 G P a$ & $3.3 G P a$ & $3.6 G P a$ \\
Flexural strength & $0.53 \mathrm{MPa}$ & $0.50 \mathrm{MPa}$ & $0.55 \mathrm{MPa}$ & $0.60 \mathrm{MPa}$ \\
Crushing strength & $1.06 \mathrm{MPa}$ & $2.0 \mathrm{MPa}$ & $2.2 \mathrm{MPa}$ & $2.4 \mathrm{MPa}$ \\
Density & $930 \mathrm{~kg} / \mathrm{m}^{3}$ & $900 \mathrm{~kg} / \mathrm{m}^{3}$ & $900 \mathrm{~kg} / \mathrm{m}^{3}$ & $900 \mathrm{~kg} / \mathrm{m}^{3}$ \\
Poisson's ratio & 0.33 & 0.33 & 0.33 & 0.33 \\
Frictional coefficient & 0.05 & 0.10 & 0.10 & 0.10 \\
\hline
\end{tabular}

\subsection{Evaluation of Sea Ice Performance for the CIVArctic Vessel}

Based on Froude scaling dimensionless ratios in modelscale and full-scale must be equal (Von Bock und Polach et al., 2014b). The relatively low ratio between crushing strength and flexural strength compared with full-scale sea ice reflects a known deficiency of model ice (see e.g. Von Bock und Polach and Ehlers (2011)). In full-scale the ratio between elastic modulus and flexural strength is considered to express the brittleness of the ice and lies well above 2000, while in model-scale this ratio is not often reached, but lower to a ratio of 1000 . In addition, different frictional coefficient values could also affect the estimates of ice resistance. As shown in Table 4, these ice properties are then modified (referring to Lubbad and Løset (2011)) for the evaluation of sea ice performance of the CIVArctic vessel.

Figures 28 and 29 present the simulation results with the modified ice properties and with the ice properties directly scaled from the model tests. As shown in Table 4 , the frictional coefficient applied in this simulation is twice of the model ice, which will considerably increase the ice resistance. An increased breaking length of ice will be created as the elastic modulus of ice is increased. The increased crushing strength will result in the increased magnitude but decreased duration of the ice crushing force. These factors can offset each other in determining the overall ice resistance. Therefore the ice model tests carried out might give a roughly good evaluation of the full-scale ice resistance, though there is a big difference between model ice and full-scale sea ice. As shown in Figures 28 and 29, there is a relatively bigger deviation between the simulation results with model ice and full-scale sea ice, when the vessel is running astern. This may be attributed to the more complicated icebreaking pattern at stern, as the two headboxes are continuously breaking ice. Hence, more sensitivity studies on the ice and ship parameters should be carried out to identify the reasons for the reduced agreement between the numerical and experimental results for the astern situation.

\section{Conclusion}

In this paper, a numerical model is used to investigate the level ice performance of a double-acting intervention vessel designed mainly for open water. The simulation results are consistent with the design intention that the stern should have enhanced ice handling capabilities compared to the bow. The reason lies in the open-water design, as ice is mainly crushed when moving ahead instead of breaking by a more efficient failure mode. Another contributor to this performance gap lies in the headboxes of the main propulsors, as these provide favorable interaction with the ice sheet, catering for more efficient icebreaking.

In terms of forward ice-going performance, it is found that the occurrence of shoulder crushing can cause in- 


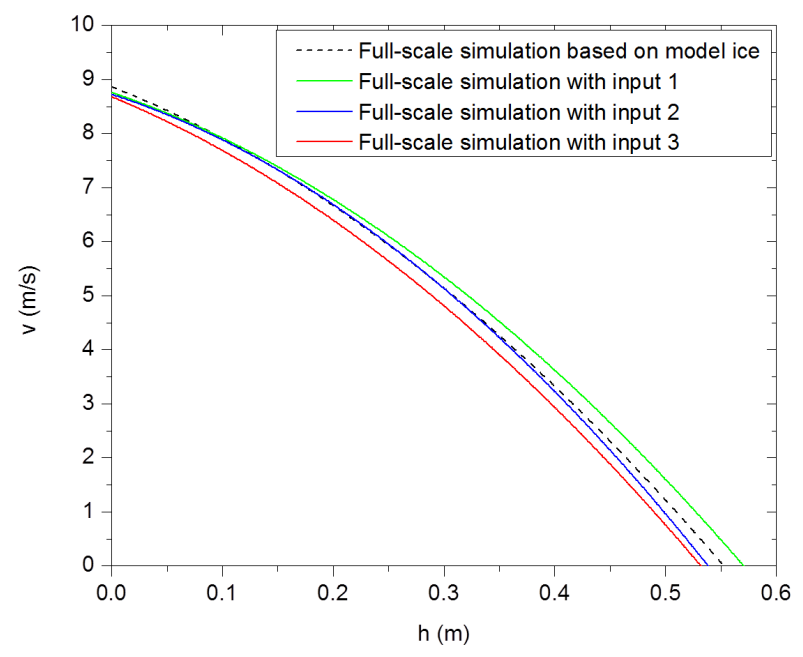

Figure 28: $h-\nu$ curve obtained when the vessel is running ahead (the full-scale simulation results with different ice parameters).

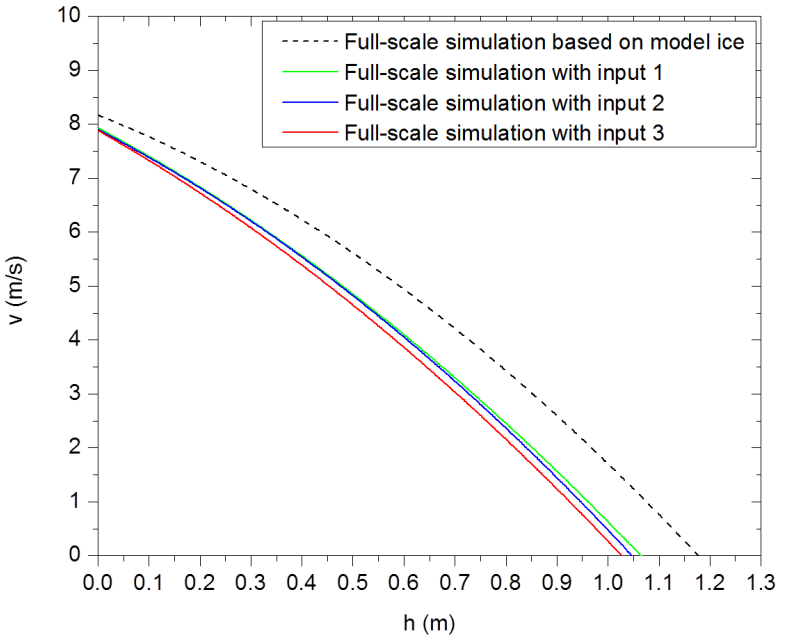

Figure 29: $h-\nu$ curve obtained when the vessel is running astern (the full-scale simulation results with different ice parameters). creased ice resistance, which may considerably impair the ship's performance in certain ice conditions. When a random variation of the crack size is considered in the numerical simulations, intermittent shoulder crushing is observed in almost all ice conditions. This will give a more consistent evaluation of the ship's performance in various ice conditions, as seen in the corresponding $h-\nu$ curves.

In terms of maneuvering, it is found that the turning performance of the vessel can be improved if an inward heel of the vessel is allowed. On average, the numerical simulations indicate that the turning circle diameter is reduced by $65 \%$ if a $3^{\circ}$ heeling angle is applied. It is also found that the turning circle diameter is reduced by about $30 \%$ when the vessel is operated stern first. The available experimental data are unfortunately not sufficient for a valid comparison with the numerical simulation results. Therefore these conclusions should be further investigated if more experimental data becomes available.

The scaling of ship speed and ice resistance is discussed by comparing the simulation results in both fullscale and model-scale. It is found that the theoretical scaling laws can be generally applied for the scaling of simulated ship speed and ice forces, while a certain deviation value should be taken into account. The effect of the different properties of scaled model ice and full-scale sea ice is also considered for the evaluation of ship performance. The simulation results imply that the model tests carried out may give a non-conservative evaluation of the full-scale sea ice performance.

In general, the numerical simulation results can supplement the experimental data by providing more information about the vessel's maneuverability in level ice and identifying the physical foundation for the exhibited performance of the vessel. However, limitations do exist in both numerical simulations and ice model tests. The propeller jet and propeller-ice interaction are not included in the numerical model, and some assumptions are made, including the approximated circular crack, normal distribution of the crack size, and decomposition of the ice resistance. The model test results are influenced by many parameters, such as the type of the model ice, size of the ice basin relative to the model, and possible edge effects. Regarding these issues, further studies and accumulation of data are required.

\section{Acknowledgments}

The authors acknowledge the support from the partners in the knowledge-based project "Construction and Intervention Vessels for Arctic Oil and Gas"(CIVArctic) and the CoE Centre for Ships and 
Ocean Structures (CeSOS). We also appreciate the constructive comments to the paper from Sören Ehlers (TUHH - Hamburg University of Technology) and Nils Albert Jenssen (Kongsberg Maritime) during review of the text.

The research is partly funded by Research Council of Norway (RCN) project no. 199567: KMB "Arctic DP", with partners Kongsberg Maritime, Statoil, and DNV GL, and partly by RCN project no. 203471: CRI SAMCoT.

\section{References}

Bazant, Z. and Guo, Z. Scaling of failure of floating sea ice plates. In 15th ASCE Engineering Mechanics Conference. American Society of Civil Engineers, 2002.

Berg, T. E., Berge, B. O., Borgen, H., Hänninen, S., Suojanen, R. A., and $\mathrm{Su}, \mathrm{B}$. Offshore vessel design for Barents Sea operations. In Proceedings of the International Conference on Port and Ocean Engineering Under Arctic Conditions. 2013.

Berg, T. E., Berge, B. O., Hanninen, S., Suojanen, R.A., Borgen, H., et al. Design considerations for an arctic intervention vessel. In OTC Arctic Technology Conference. Offshore Technology Conference, 2011.

Enkvist, E. On the ice resistance encountered by ships operating in the continuous mode of icebreaking. Technical report, 1972.

Enkvist, E., Varsta, P., and Riska, K. The ship-ice interaction. In Proceedings of the 5th International Conference on Port and Ocean Engineering under Arctic Conditions., volume 2. 1979.

Faltinsen, O. Sea loads on ships and offshore structures, volume 1. Cambridge university press, 1993.

Izumiyama, K., Kitagawa, H., Koyama, K., and Uto, S. A numerical simulation of ice-cone interaction. In 11th IAHR international symposium on ice. 1992.

Jones, S. J. Ships in ice-a review. In 25th Naval Hydrodynamics. 2004.

Kjerstad, Ø. K., Skjetne, R., and Berge, B. O. Constrained nullspace-based thrust allocation for heading prioritized stationkeeping of offshore vessels in ice. In Proceedings of the International Conference on Port and Ocean Engineering Under Arctic Conditions. 2013.

Leiviskä, T. Performance and dp tests in ice with civarctic vessel. Technical report AARC Report A454, Aker Arctic, 2011.
Lindqvist, G. A straightforward method for calculation of ice resistance of ships. In Proceedings of the 10th International Conference on Port and Ocean Engineering Under Arctic Conditions. 1989.

Liu, J., Lau, M., and Williams, F. M. Mathematical modeling of ice-hull interaction for ship maneuvering in ice simulations. 2006.

Lubbad, R. and Løset, S. A numerical model for realtime simulation of ship-ice interaction. Cold Regions Science and Technology, 2011. 65(2):111-127. doi:10.1016/j.coldregions.2010.09.004.

Martio, J. Numerical simulation of vessel's maneuvering performance in uniform ice. informally published manuscript, Ship Laboratory, Helsinki University of Technology, Espoo, Finland, 2007. pages 1-30.

McKindra, C. and Lutton, T. Statistical analysis of broken ice dimensions generated during 140-ft wtgb icebreaking trials. In Proceedings of the 6th International Conference on Port and Ocean Engineering under Arctic Conditions. 1981.

Metrikin, I., Kerkeni, S., Jochmann, P., and Løset, S. Experimental and numerical investigation of dynamic positioning in level ice. In ASME 2013 32nd International Conference on Ocean, Offshore and Arctic Engineering. American Society of Mechanical Engineers, pages V006T07A019-V006T07A019, 2013.

Newmark, N. M. A method of computation for structural dynamics. In Proc. ASCE, volume 85. pages 67-94, 1959.

Nguyen, D. T., Sørbø, A., and Soerensen, A. Modelling and control for dynamic positioned vessels in level ice. In Manoeuvring and Control of Marine Craft. pages 229-236, 2009. doi:10.3182/20090916-3-BR3001.00036 .

Von Bock und Polach, E. S., Rüdiger, Erikstad, S. O., et al. A decision-based design approach for ships operating in open water and ice. Journal of Ship Production and Design, 2014a. doi:10.5957/JSPD.30.3.140001.

Von Bock und Polach, R. and Ehlers, S. Heave and pitch motions of a ship in model ice: An experimental study on ship resistance and ice breaking pattern. Cold Regions Science and Technology, 2011. 68(1):49-59. doi:10.1016/j.coldregions.2011.04.007.

Von Bock und Polach, R., Ehlers, S., et al. On the scalability of model-scale ice experiments. In 33rd 
International Conference on Ocean, Offshore Mechanics and Arctic Engineering. American Society of Mechanical Engineers, 2014b.

Riska, K., Leiviskä, T., Nyman, T., Fransson, L., Lehtonen, J., Eronen, H., and Backman, A. Ice performance of the swedish multi-purpose icebreaker tor viking ii. In Proceedings of the 16th International Conference on Port and Ocean Engineering under Arctic Conditions, volume 2001. pages 849865, 2001.

Riska, K., Wilhelmson, M., Englund, K., and Leiviskä, T. Performance of merchant vessels in ice in the baltic. Research Report NO. 52. Ship Laboratory, Helsinki University of Technology, 1997.

Sawamura, J., Tsuchiya, H., Tachibana, T., and Osawa, N. Numerical modeling for ship maneuvering in level ice. In 20th IAHR international symposium on ice. 2010.

$\mathrm{Su}, \mathrm{B}$. Full-scale and model scale simulations of the level ice performance of civarctic vessel. Research Report No. 530529, MARINTEK, Trondheim, Norway, 2012.

Su, B., Kjerstad, Ø. K., Skjetne, R., and Berg, T. E. Ice-going capability assessment and DP-Ice Capability Plot for a double acting intervention vessel in level ice. In Proceedings of the International Conference on Port and Ocean Engineering Under Arctic Conditions. 2013.

$\mathrm{Su}$, B., Riska, K., and Moan, T. A numerical method for the prediction of ship performance in level ice. Cold Regions Science and Technology, 2010a. 60(3):177-188. doi:10.1016/j.coldregions.2009.11.006.

$\mathrm{Su}$, B., Riska, K., and Moan, T. Numerical simulation of ship turning in level ice. In $A S M E$ 2010 29th International Conference on Ocean, Offshore and Arctic Engineering. American Society of Mechanical Engineers, pages 751-758, 2010b. doi:10.1115/OMAE2010-20110.

Su, B., Riska, K., and Moan, T. Numerical simulation of local ice loads in uniform and randomly varying ice conditions. Cold Regions
Science and Technology, 2011. 65(2):145-159. doi:10.1016/j.coldregions.2010.10.004.

Su, B., Riska, K., Moan, T., and Berg, T. Full-scale and model-scale simulations of a double acting intervention vessel operating in level ice. In 21th IAHR international symposium on ice. 2012.

$\mathrm{Su}$, B., Skjetne, R., and Berg, T. E. Numerical assessment of a double-acting offshore vessel's performance in level ice with experimental comparison. Cold Regions Science and Technology, 2014. 106:96-109. doi:10.1016/j.coldregions.2014.06.012.

Tan, X. Numerical Investigation of Ship's ContinuousMode Icebreaking in Level Ice. Ph.D. thesis, Norwegian University of Science and Technology, 2014.

Tan, X., Su, B., Riska, K., and Moan, T. A six-degreesof-freedom numerical model for level ice-ship interaction. Cold Regions Science and Technology, 2013. 92:1-16. doi:10.1016/j.coldregions.2013.03.006.

Tatinclaux, J. Ice floe distribution in the wake of a simplified wedge. In 15th International Conference on Ocean, Offshore Mechanics and Arctic Engineering. American Society of Mechanical Engineers, 1986.

Valanto, P., Jones, S. J., Enkvist, E., and Izumiyama, K. The resistance of ships in level ice. discussion. author's closure. Transactions-Society of Naval Architects and Marine Engineers, 2001. 109:53-83.

Varsta, P. On the mechanics of ice load on ships in level ice in the baltic sea. Research Report 11, Technical Research Centre of Finland, Espoo, Finland, 1983.

Vocke, M., Ranki, E., Uuskallio, A., Niini, M., Wilkman, G., et al. Experience from vessels operating in ice in the double acting principle. In OTC Arctic Technology Conference. Offshore Technology Conference, 2011.

Wang, S. A dynamic model for breaking pattern of level ice by conical structures. Ph.D. thesis, Department of Mechanical Engineering, Helsinki University of Technology, Finland, 2001.

Wilkman, G., Forsen, A., and Mattsson, T. Recent advancements in ice model testing at aker arctic. In 20th IAHR international symposium on ice. 2010. 